\title{
Correction to: Live fuel moisture content (LFMC) time series for multiple sites and species in the French Mediterranean area since 1996
}

\author{
N. Martin-StPaul ${ }^{1} \cdot$ F. Pimont ${ }^{1} \cdot$ J. L. Dupuy ${ }^{1} \cdot$ E. Rigolot ${ }^{1} \cdot$ J. Ruffault ${ }^{1} \cdot$ H. Fargeon ${ }^{1} \cdot$ E. Cabane ${ }^{2} \cdot$ Y. Duché $^{3}$. $^{-}$ \\ R. Savazzi ${ }^{3} \cdot$ M. Toutchkov $^{1}$
}

Published online: 2 July 2018

(C) INRA and Springer-Verlag France SAS, part of Springer Nature 2018

\section{Correction to: Annals of Forest Science}

https://doi.org/10.1007/s13595-018-0729-3

The original version of this article has been corrected to reflect Open Access. Additionally, this correction stands to correct what was a broken hyperlink in the key message section of the article as well as an error related to the replacement of Supplementary File 13595_2018_729_MOESM2_ESM.xlsx. The original article has been corrected.

The online version of the original article can be found at https://doi.org/ 10.1007/s13595-018-0729-3

N. Martin-StPaul

nicolas.martin@inra.fr

URFM, INRA, Avignon, France

2 DPFM, Délégation à la Protection de la Forêt Méditerranéenne, Marseille, France

3 Mission Zonale DFCI, ONF, Aix en Provence, France 